\title{
EFICÁCIA DO EXTRATO AQUOSO DO Triticum vulgare NO TRATAMENTO DE RADIODERMATITES GERADAS PELO USO DA RADIOTERAPIA EM GATOS
}

\author{
Alexandre Lima de Andrade ${ }^{1}$, Maria Cecília Rui Luvizotto ${ }^{1}$, Silmara Sanae \\ Sakamoto ${ }^{1}$, Talita Floering Brêda Souza ${ }^{1}$, Marco Antônio Rodrigues Fernandes ${ }^{2}$ \\ 1 Universidade Estadual Paulista (UNESP) - Campus de Araçatuba - landrade@fmva.unesp.br \\ 2 Universidade Estadual Paulista (UNESP) - Campus de Botucatu.
}

\begin{abstract}
RESUMO: O uso de radiações ionizantes no tratamento de doenças oncológicas em medicina veterinária tem crescido nos últimos anos. De maneira geral, os animais têm tolerado muito bem os tratamentos com elementos radioativos, no entanto, os efeitos deletérios que podem ocorrer nem sempre são possíveis de serem controlados, principalmente àqueles relativos às queimaduras cutâneas. Sendo assim, este trabalho estudou os efeitos do creme de Triticum vulgare no tratamento de radiodermatites de 10 gatos portadores de carcinoma escamo celular (CEC) que foram tratados com a radioterapia como modalidade única de terapia. Utilizou-se o fármaco topicamente e diariamente até a completa cicatrização das feridas por queimadura. Frente aos achados, concluiuse pelos efeitos benéficos do mesmo, pois ele permitiu a formação de tecido de granulação e epitelização das feridas com reparação epidérmica não exuberante, de boa qualidade e cosmética, considerando-se os efeitos deletérios que podem advir de tratamentos oncológicos.
\end{abstract}

Palavras-chave: gatos; queimaduras cutâneas; radioterapia; Triticum vulgare

\section{EFFICACY OF THE AQUEOUS EXTRACT Triticum vulgare IN RADIODERMATITIS TREATMENT GENERATED BY THE USE OF RADIOTHERAPY IN CATS}

\begin{abstract}
The use of ionizing radiation in the treatment of oncological diseases in veterinary medicine has grown in recent years. In general, these animals are very well tolerated by the treatment with radioactive elements; however, the harmful effects that may occur are not always able to be controlled, particularly those relating to skin burns. Then, the purpose of this study was to evaluate the effects of aqueous extract of Triticum vulgare in treat of 10 cats radiodermatitis with squamous cell carcinoma (SCC), which were treated with radiotherapy as single modality treatment. The drug was used topically and daily until complete healing of wounds. Based on the findings, it may concluded beneficial effects of the drug, because it allowed the formation of granulation tissue and epithelization of wounds with epidermal repair not exuberant, good-quality cosmetics and, considering the deleterious effects that can result from cancer treatments.
\end{abstract}

Key Words: cats; cutaneous burns; radiotherapy; Triticum vulgare 


\section{INTRODUÇÃO}

O uso de radiações ionizantes no tratamento de doenças em medicina veterinária já é citado desde o início do século XX. De maneira geral, os animais têm tolerado muito bem os tratamentos com elementos radioativos (Banks et al., 1972; Blackwood e Dobson, 1998). Quanto à utilização da teleterapia e braquiterapia nos tumores de pele em animais, as reações tardias mais comumente observadas são a discromia de pele e alopecia, efeitos radiobiológicos que podem ser reversíveis após 0 tratamento, dependendo da taxa de dose e da dose total de radiação, bem como a região a ser tratada. No entanto, as complicações precoces que ocorrem logo após o início do tratamento ainda constituem-se em assunto polêmico, e de difícil resolução. Dentre elas, destacam-se as radiodermatites, que em casos severos evoluem para queimaduras e radionecrose importantes. Tais lesões também são dependentes da dose total empregada no tratamento da neoplasia, assim como - fracionamento e distribuição da mesma (Mole, 1987).

A cicatrização de ferimentos e queimaduras é um processo biológico preferencial. Trata-se de uma combinação de eventos físicos, químicos e celulares que restaura 0 tecido ou o substitui por colágeno (Fossum, 2001). No entanto, tais ferimentos requerem tratamentos adequados para que ocorra a reparação tecidual. Neste sentido, algumas opções de preparações tópicas estão disponíveis no mercado, cada uma com suas propriedades que podem ou não interferir nas fases da cicatrização (Banks, 1972; Blackwood e Dobson, 1998; Ertekin et al, 2004; Blecha e Guedes, 2005).
O extrato aquoso da planta
Triticum vulgare (BANDVET ${ }^{\circledR}$ -
Schering-Plough//ntervet) composição complexa contém extratos vegetais bioestimulantes e exerce a sua ação farmacológica basicamente por meio de estimulação da atividade fibroblástica, além de possuir efeito antiinflamatório local e alto poder cicatricial em feridas provocadas pelos mais variados agentes vulnerantes. A sua eficácia foi comprovada no tratamento de feridas sujas e infectadas (Andrade et al., 2003) e até úlceras de córnea em cães (Ortiz et al., 2005).

Neste sentido, este trabalho teve por objetivo avaliar clinicamente os efeitos do Triticum vulgare, sob a forma de creme, em radiodermatites geradas pelo emprego da radioterapia no tratamento de tumores cutâneos em gatos.

\section{MATERIAL E MÉTODOS}

Foram estudados 10 gatos, com e sem raça definida (SRD), seis machos e quatro fêmeas, com médias de peso e idade de 4,2 $\mathrm{kg}$ e 3,2 anos, respectivamente. Os animais foram atendidos no Serviço de Clínica Cirúrgica de Pequenos Animais do Hospital Veterinário da Unesp - campus de Araçatuba. Os gatos apresentavam formações cutâneas planas exulcerativas e infectadas em diferentes localizações, com evolução média de um mês. Inicialmente, todos os animais foram submetidos a exame físico geral na busca de outras intercorrências clínicas associadas. Concluído o exame físico geral, procedeu-se a colheita de material das diferentes lesões cutâneas para realização de exame citopatológico. Tal procedimento foi realizado por meio de "imprint" ou PBA. As lâminas foram coradas pelo método 
Quadro 1 - Características dos pacientes, diagnóstico, tratamento e tempo de cicatrização dos gatos submetidos ao tratamento de queimaduras de pele após radioterapia com Triticum vulgare creme.

\begin{tabular}{|c|c|c|c|c|c|c|}
\hline Animal & Raça & Sexo & ldade & Diagnóstico & Tratamento & $\begin{array}{l}\text { Tempo de } \\
\text { cicatrização }\end{array}$ \\
\hline$\overline{1}$ & SRD & $\bar{F}$ & 3 anos & CEC na pina & Dermopan + BV & 68 dias \\
\hline 2 & SRD & $\mathrm{F}$ & 2 anos & $\begin{array}{l}\text { CEC na } \\
\text { pálpebra }\end{array}$ & $\begin{array}{c}\text { Betaterapia }(\mathrm{Sr}-90)+ \\
\text { BV }\end{array}$ & 45 dias \\
\hline 3 & $\begin{array}{c}\text { Gato } \\
\text { doméstico }\end{array}$ & M & 3 anos & CEC na pina & Dermopan + BV & 45 dias \\
\hline 4 & SRD & M & 3 anos & CEC na face & $\begin{array}{c}\text { EC + Betaterapia } \\
(\text { Sr-90) + BV }\end{array}$ & 20 dias \\
\hline 5 & SRD & M & 4 anos & CEC na pina & Dermopan + BV & 67 dias \\
\hline 6 & SRD & $\mathrm{F}$ & 5 anos & CEC na pina & Dermopan + BV & 49 dias \\
\hline 7 & $\begin{array}{c}\text { Gato } \\
\text { doméstico }\end{array}$ & M & 1 ano & $\begin{array}{l}\text { CEC na } \\
\text { pálpebra }\end{array}$ & Dermopan + BV & 50 dias \\
\hline 8 & SRD & M & 2 anos & CEC na pina & Dermopan + BV & 60 dias \\
\hline 9 & SRD & M & 4 anos & $\begin{array}{l}\text { CEC no } \\
\text { membro }\end{array}$ & $\begin{array}{c}\text { EC + Betaterapia } \\
(\text { Sr-90) }+ \text { BV }\end{array}$ & 21 dias \\
\hline 10 & SRD & $\mathrm{F}$ & 5 anos & CEC na pina & Dermopan + BV & 40 dias \\
\hline
\end{tabular}

de panótico rápido. No Quadro 1 são apresentados os dados referentes aos pacientes estudados.

Confirmado o diagnóstico de neoplasia cutânea, os gatos foram tratados empregando-se: 1) excisão cirúrgica da lesão obedecendo a margens de $2,0 \mathrm{~cm}$ de segurança, em associação com sessão única de betaterapia com Estrôncio-90, 2) sessões fracionadas de radioterapia exclusiva com Raios-X (Dermopan $\left.{ }^{\circledR}\right)$ ou 3) sessões fracionadas de betaterapia com Estrôncio-90. Como tratamento adjuvante em combate às reações cutâneas de radiodermatite ou queimaduras, cada um deles, em seu local de lesão, recebeu a aplicação do creme do extrato aquoso de Triticum vulgare, a cada 12 horas, em quantidade suficiente a cobrir toda a lesão e bandagem não aderente como camada de contato (Adaptic®), Johnson \& Johnson, USA).. Para que fatores comportamentais de automutilação não influenciassem na cicatrização das feridas, os animais utilizaram colar do tipo Elizabetano.

Foram incluídos no estudo apenas os pacientes cujas feridas apresentavam uma área média inicial de até 2,0 $\mathrm{cm}^{2}$, para que pudesse comparar os resultados do tratamento a ser empregado.

\section{Avaliação Clínica}

As feridas por queimadura foram avaliadas semanalmente até o momento da sua cicatrização completa. Salientase que o tempo de cicatrização foi registrado para obtenção da média de eficiência do tratamento. Os fenômenos avaliados foram: presença ou não de secreção, formação de tecido de granulação, epitelização, tempo de contração da ferida e presença de cicatriz hipertrófica.

\section{RESULTADOS E DISCUSSÃO}

Os animais estudados apresentavam lesões cutâneas em diferentes regiões do corpo (Tabela 1; Fig. 1), porém com maior freqüência na região da pina (60\% dos casos) (Fig. 1B). Pelo histórico clínico e aspectos das lesões, firmou-se o diagnóstico presuntivo de carcinoma de células escamosas (CEC). O CEC é o tumor cutâneo mais freqüente em cães, representando aproximadamente cerca de um terço de todos os tumores encontrados nessa espécie (Vail e Withrow, 2001). Em 

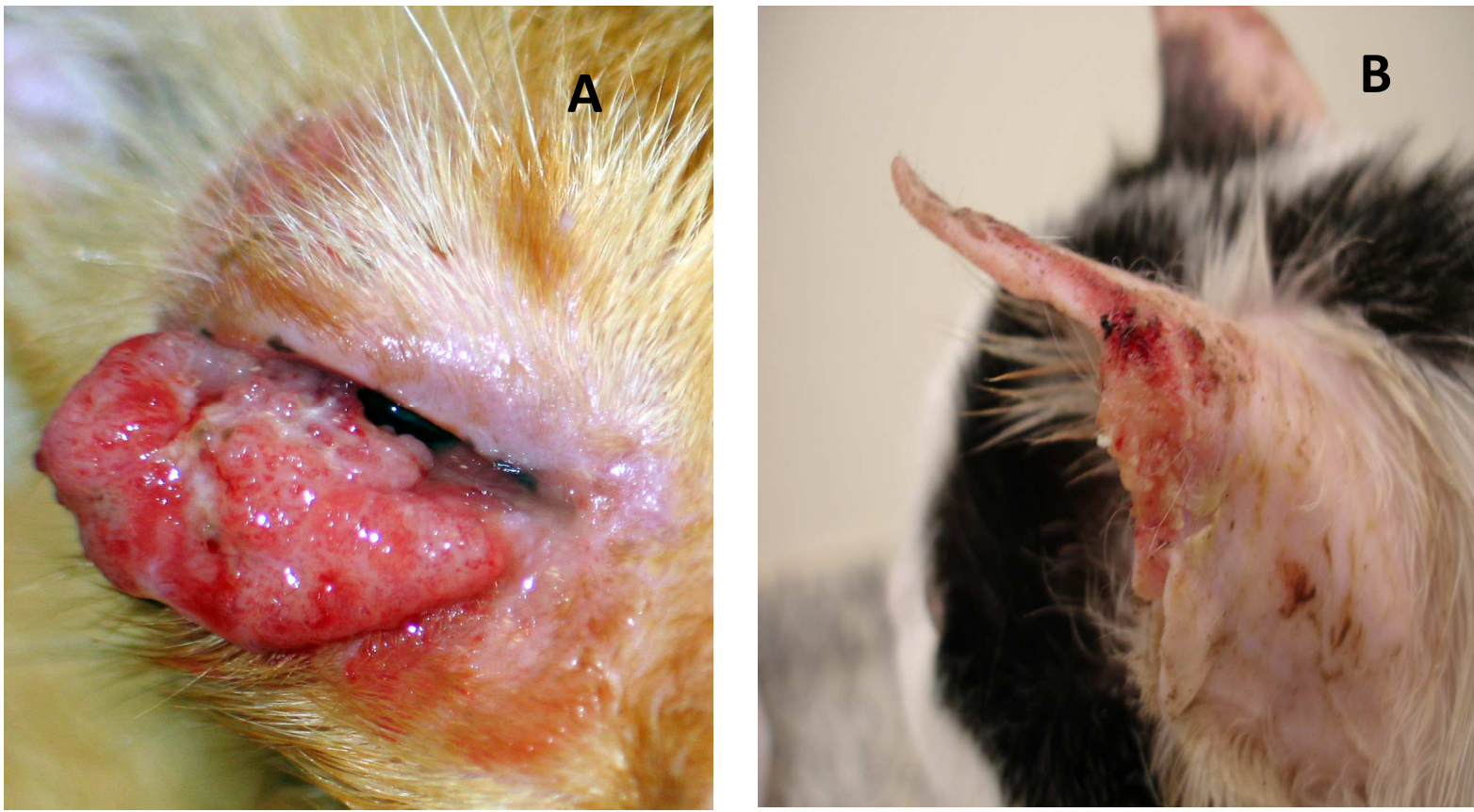

Figura 1 - Imagem fotográfica de gatos com CEC. Em A (animal 2), neoformação com aspecto de couve-flor na pálpebra inferior direita. Notar exsudação inflamatória e pequenas áreas de necrose. Imagem antes do tratamento radioterápico. Em B (animal 5), lesão exulcerativa na pina com destruição tecidual por necrose. Notar perda do contorno anatômico da borda externa da orelha por necrose e crostas aderidas.

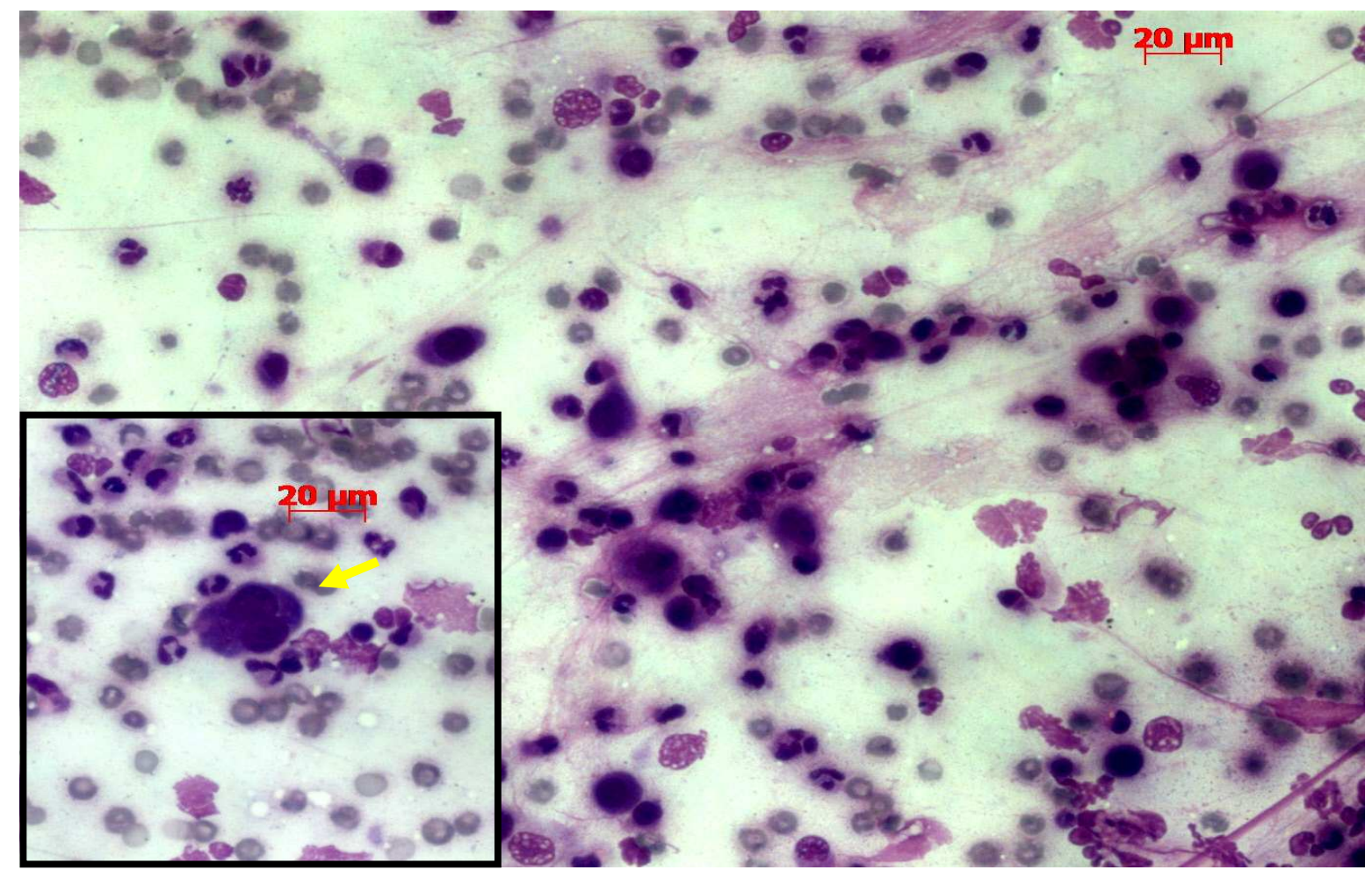

Figura 2 - Fotomicrografia de exame citológico ("imprint") de neoformação palpebral com diagnóstico de CEC na pálpebra inferior direita (animal 2). Observa-se densa população de células escamosas queratinizadas com núcleos picnóticos ou anucleadas. Observam-se algumas células com significante atipia incluindo intensa anisocitose, pleomorfirmo nuclear e nucléolo grande e proeminente. De permeio à estas células observa-se a presença de neutrófilos e células binucleadas (destaque abaixo e à esquerda - seta). Panótico rápido, 40X. 
gatos, é o segundo mais freqüente, perdendo destaque para os tumores do tecido linfóide (Miller et al., 1991). O diagnóstico presuntivo foi confirmado pelo exame citológico, cujo material da lesão foi obtido por meio de "imprint" ou PBA (Fig. 2). Não se encontraram óbices para realização de tais manobras, que foram fundamentais para a confirmação diagnóstica, além de se tratar de um procedimento rápido, menos invasivo e de baixo custo.

Todos os animais apresentaram tecido de granulação e epitelização das feridas por queimadura, no entanto, em períodos variados. As lesões não se encontravam infectadas e levaram, em média, 35 dias para cicatrizarem após a última sessão de radioterapia planejada para cada caso (Fig. 3 e 4). Este período foi ainda maior nos casos em que as lesões cutâneas do CEC eram mais extensas e seus tratamentos foram realizados empregando-se 0 Dermopan® (casos 5, 6 e 8).

Neste estudo observou-se que o tempo de tratamento de cicatrização das feridas por queimadura foi superior ao observado por Andrade et al. (2003), que trataram feridas sujas e infectadas de cães com o mesmo princípio ativo. Aos sete dias, em média, após a última sessão de radioterapia, observou-se que as crostas geradas pela excessiva exsudação inflamatória pela ação da queimadura por radiação, ainda eram abundantes (Fig. 3B), regredindo em média após 25 dias de tratamento. Ao final deste período, as feridas exibiam um tecido de granulação brilhante preenchendo toda área da ferida com início de epitelização, demonstrado por diminuição das áreas das lesões. Isto indica a eficiência do planejamento radioterápico na cura do tumor em questão e efeito adjuvante do Triticum vulgare em conter os efeitos nocivos da radioterapia à pele. A resposta da pele à radiação ionizante pode envolver múltiplos focos inflamatórios. endotélio é conhecido por desempenhar um papel crítico na radiação induzida por lesão vascular. Além disso, a disfunção endotelial reflete em uma diminuição da disponibilidade de óxido nítrico ao tecido cutâneo (Holler et al., 2009). Tal fato pode ser comprovado durante todo tratamento com a radiação e em todos os casos tratados, onde a cada limpeza das feridas observava-se um sangramento abundante que era contido após administração tópica do creme, que no entender dos autores deste estudo atuava como um tampão capaz de conter a hemorragia. Porém, esse evento vascular reduziu gradativamente quando a fases de reparação tecidual se iniciava. $O$ emprego de estatinas ou preparações a base de sulfato de Zinco tem sido relatados para preservar a função endotelial como adjuvante à prevenção ou redução das queimaduras cutâneas geradas pelo tratamento radioterápico por meio da sua ação antioxidante e antinflamatória (Ertekin et al., 2004; Holler et al., 2009). No entanto, tais fármacos não foram empregados concomitantemente, pois fugiria dos objetivos de avaliar os efeitos isolados do Triticum vulgare no tratamento de radiodermatites. Mas, frente aos resultados pode-se inferir que o extrato aquoso do Triticum vulgare é uma alternativa viável e disponível no mercado para uso em radioterapia.

Salienta-se ainda, os benefícios tópicos do fármaco testado no controle de feridas por queimadurageradas pelo emprego da radiação, ainda que isso tenha ocorrido em períodos mais avançados quando comparado ao que já fora relatado (Matera et al., 2002; Andrade et al., 2003). Justifica-se, ainda que à semelhança nesses estudos em que o Triticum vulgare promoveu uma evolução cicatricial de feridas por segunda intenção favorável, além do efeito anabólico e de incremento protéico deste extrato aquoso que favo- 

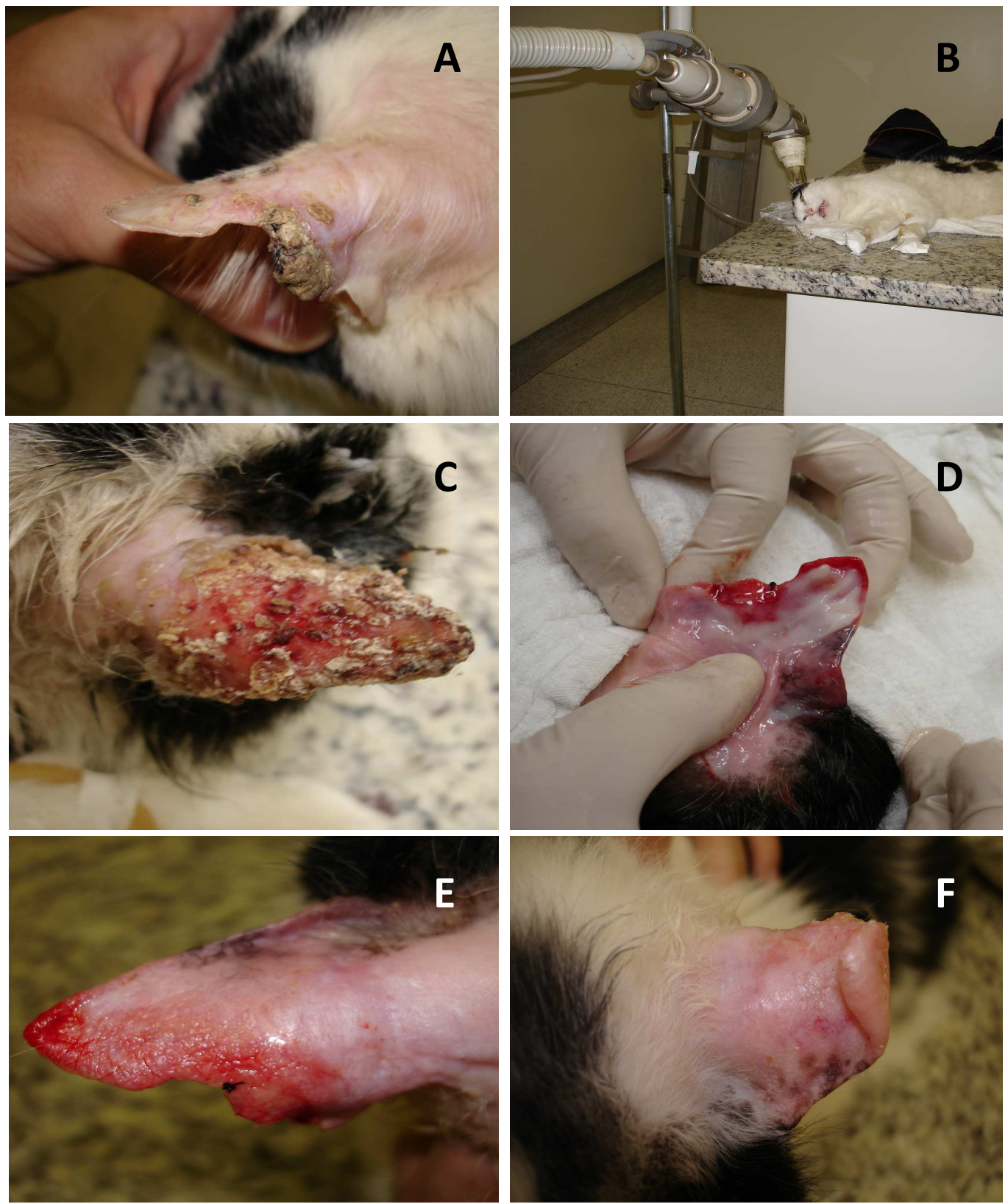

Figura 3 - Imagem fotográfica da evolução de CEC na pina esquerda (animal 5) tratado com Raios-X de alta frequencia (Dermopan ${ }^{\circledR}$ ) e curativos diários de extrato aquoso de Triticum vulgare (BandVet@). Em A, lesão exulcerativa na pina com destruição tecidual por necrose antes do tratamento. Notar perda do contorno anatômico da borda externa da orelha por necrose e crostas aderidas. Em B, animal anestesiado sendo submetido ao procedimento de radioterapia empregando-se o Dermopan ${ }^{\circledR}$. Em C, evolução do mesmo caso após o cumprimento do protocolo terapêutico de radioterapia. Notar queimadura por radiação (radiodermatite) intensa com presença de crostas em abundância decorrente a exsudação inflamatória. Em D, curativo asséptico da radiodermatite utilizando uma camada generosa do creme do extrato aquoso de Triticum vulgare. Em E, evolução do caso após 56 dias de tratamento. Notar diminuição considerável da radiodermatite e manutenção do tecido viável. Em F, aspecto final do tratamento aos 67 dias. Notar reparação epidérmica não exuberante, de boa qualidade e cosmética.

recem a reepitelização, este tratamento permitiu uma reparação epidérmica não exuberante, de boa qualidade e cosmé- tica. E Justifica-se que a cicatrização ocorreu mais tardiamente em função das repetidas injúrias teciduais a cada 


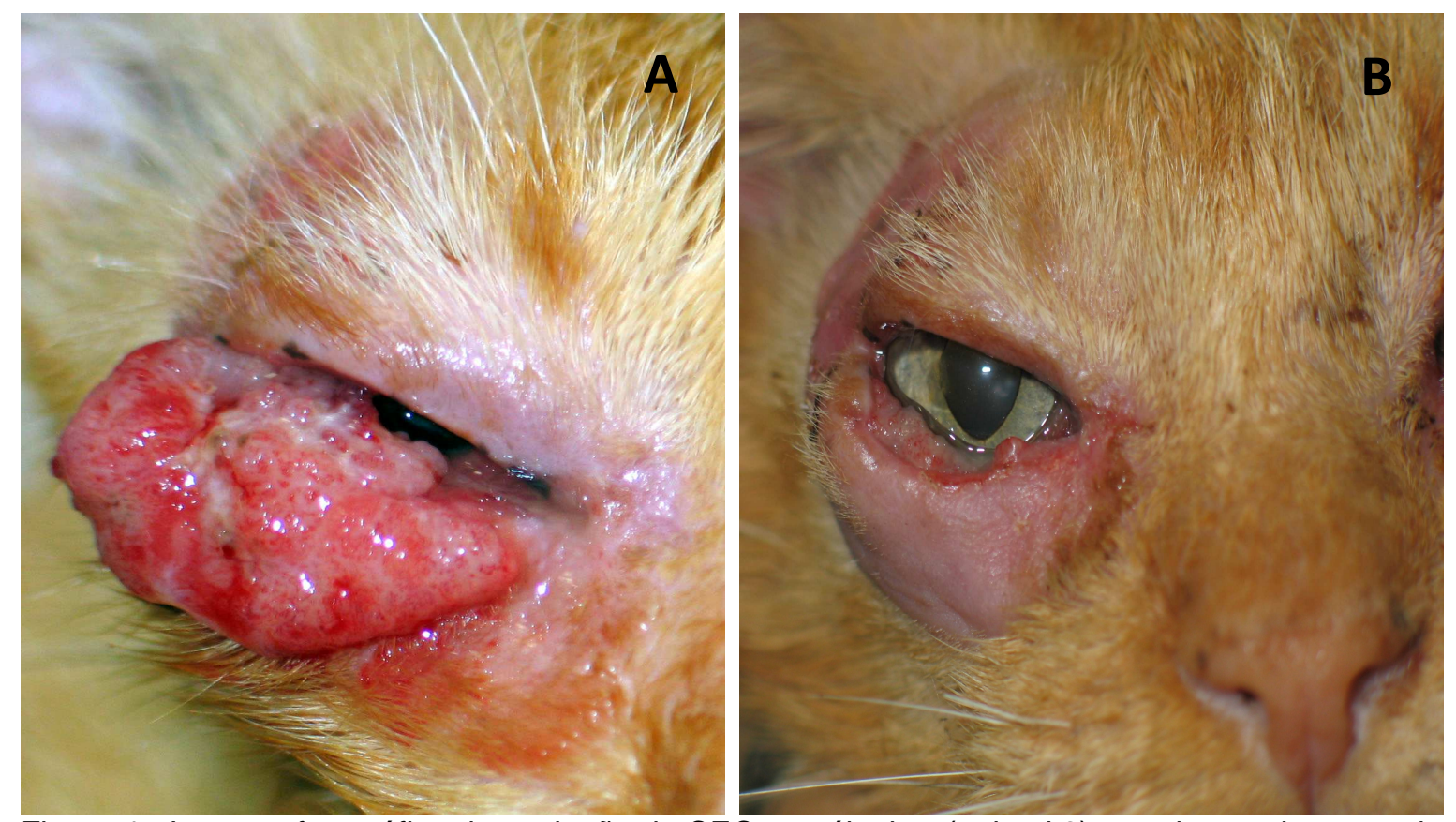

Figura 4 - Imagem fotográfica da evolução de CEC na pálpebra (animal 2) tratado com betaterapia com Estrôncio-90 e curativos diários de extrato aquoso de Triticum vulgare (BandVet®). Em A, CEC avançado na pálpebra inferior direita antes do tratamento. Em B, aspecto final após o tratamento radioterápico (45 dias) e controle da radiodermatite.

sessão de radioterapia, algo que normalmente não ocorre quando tratamos outros tipos de feridas em que além dos cuidados tópicos, toma-se o cuidado em coibir outros fatores que inibem processo de reparo, e que causam uma reação inflamatória extensa que destrói a matriz extracelular, prolongando as fases inflamatórias e de reparo (Pereira e Arias, 2002).

$$
\text { Ainda, ressalta-se a importância }
$$
do uso de bandagens, preferencialmente as não aderentes, como camada de contato, para assegurar a permanência do fármaco em contato com a lesão, além de promover proteção ao ferimento contra agentes externos. Neste estudo, optouse pelo uso de bandagem não aderente, por se tratar de material semi-oclusivo. Tais propriedades permitem a retenção da umidade para promover a epitelização e impedir a desidratação do ferimento, evitando, assim, maceração tecidual (Fossum, 2001).
E por fim, acredita-se que o extrato aquoso do Triticum vulgare tenha exercido suas possíveis ações bactericidas ou bacteriostáticas nos casos aqui estudados conforme reportaram Andrade et al. (2003), pois não se observou a presença de exsudato purulento contaminado em nenhum momento de avaliação durante o tratamento, o que se considera outro ponto de impacto positivo no tratamento das radiodermatites.

\section{CONCLUSÃO}

O extrato aquoso do Triticum vulgare foi eficaz no tratamento de radiodermatites geradas pela o emprego da radiação ionizante no tratamento de gatos com carcinoma escamo-celular. Embora estudos futuros abordando aspectos físico-químicos mais profundos sejam necessários, o fármaco tópico em questão deve ser considerado como uma alternativa viável para o tratamento das reações cutâneas que ocorrem no 
decorrer de terapias oncológicas empregando-se a radioterapia.

\section{REFERÊNCIAS}

ANDRADE A.L., LUVIZOTTO, M.C.R., BEVILACQUA, L. et al. Análises clínica, morfológica e imunohistoquímica do uso do Triticum vulgare na cicatrização de feridas sujas e infectadas em cães. A Hora Veterinária, v.23, n.136, p.16-20, 2003.

BANKS W.C.; ROBERTS R.; MORRIS E. et al. Radiotherapy techniques in veterinary medicine. Journal of American Veterinary Medical Association, v.160, n.4, p.446-50, 1972.

BLACKWOOD L.; DOBSON J. Radiotherapy in small animal oncology. In Practice, v.20, n.1, p.59-70, 1998.

BLECHA, F.P.; GUEDES, M.T.S. Tratamento de radiodermatite no paciente oncológico: subsídios para intervenções em enfermagem. Revista

Brasileira de Cancerologia, v.52, n.2, p.15163, 2005.

ERTEKIN M.V., KOC, M., KARSKIOGLU, I. et al. The effect of zinc sulphate in the prevention of radiation-induced dermatitis. Journal of Radioterapy Research, v.45, n.4, p.543-548, 2004.

FOSSUM T.W. Tratamento de feridas. In: Fossum (Ed), Cirurgia de Pequenos Animais. Roca, São Paulo, p.101-118, 2001.
HOLLER V., BUARD, V., GAUGLER, M.H. et al. Pravastatin limits radiation-induced vascular dysfunction in the skin. Journal of Investigative in Dermatology, v.129, n.5, p.1280-1291, 2009.

MATERA J.M., FANTONI, D.T., TARTARUNAS, A.C. et al. Ensaio de avaliação de eficácia e de exeqüibilidade de uso do creme ou gaze impregnada com Triticum vulgare em feridas cutâneas. $1^{\circ}$. fase experimental. $2^{\circ}$. fase clínica. Vet News, v.58, p.4-7, 2002.

MILLER M.A., NELSON, S.L., TURK, J.R. et al. Cutaneous neoplasia in 340 cats. Veterinary Pathology, v.28, n.5, p.389-395, 1991.

MOLE B. Radiodermatitis. Presse Medical, v.16, n.36, p.1802-1805, 1987.

ORTIZ J.P.D., LAUS J.L., BRITO F.L.C. et al. Effects on BandVet on superficial keratectomies healing in dog. In: WORLD SMALL ANIMAL VETERINARY ASSOCIATION, 30., 2005, México. Proceedings....México: Small Animal Veterinary Association, 2005. [cd-room].

PEREIRA A.M.; ARIAS M.V.B. Manejo de feridas em cães e gatos - revisão. Clínica Veterinária, v.38, p.38-42, 2002.

VAIL M.S.; WITHROW S.J. Tumors of the skin and subcutaneous tissues. In.: WITHROW S.J. \& MacEWEN. (Ed.), Small Animal Oncology. 3.ed. Saunders, Philadelphia, p.233-60, 2001. 